\title{
Development and prospects of the regional MiKlip decadal prediction system over Europe: predictive skill, added value of regionalization, and ensemble size dependency
}

\author{
Mark Reyers $^{1}$, Hendrik Feldmann ${ }^{2}$, Sebastian Mieruch ${ }^{2,3}$, Joaquim G. Pinto ${ }^{2}$, Marianne Uhlig ${ }^{2,4}$, \\ Bodo Ahrens ${ }^{5}$, Barbara Früh ${ }^{6}$, Kameswarrao Modali ${ }^{7}$, Natalie Laube ${ }^{2}$, Julia Moemken ${ }^{1,2}$, \\ Wolfgang Müller ${ }^{7}$, Gerd Schädler ${ }^{2}$, and Christoph Kottmeier ${ }^{2}$ \\ ${ }^{1}$ Institute for Geophysics and Meteorology, University of Cologne, Cologne, Germany \\ ${ }^{2}$ Institute for Meteorology and Climate Research (IMK-TRO), \\ Karlsruhe Institute of Technology (KIT), Karlsruhe, Germany \\ ${ }^{3}$ Alfred Wegener Institute for Polar and Marine Sciences, Bremerhaven, Germany \\ ${ }^{4}$ School of Geography, Environment and Earth Sciences, \\ Victoria University of Wellington, Wellington, New Zealand \\ ${ }^{5}$ Institute for Atmospheric and Environmental Sciences, \\ Goethe University Frankfurt a. M., Frankfurt a. M., Germany \\ ${ }^{6}$ Deutscher Wetterdienst (DWD), Offenbach, Germany \\ ${ }^{7}$ Max Planck Institute for Meteorology, Hamburg, Germany
}

Correspondence: Mark Reyers (mreyers@meteo.uni-koeln.de)

Received: 25 July 2017 - Discussion started: 4 September 2017

Revised: 13 February 2019 - Accepted: 1 March 2019 - Published: 20 March 2019

\begin{abstract}
The current state of development and the prospects of the regional MiKlip decadal prediction system for Europe are analysed. The MiKlip regional system consists of two 10-member hindcast ensembles computed with the global coupled model MPI-ESM-LR downscaled for the European region with COSMO-CLM to a horizontal resolution of $0.22^{\circ}(\sim 25 \mathrm{~km})$. Prediction skills are computed for temperature, precipitation, and wind speed using E-OBS and an ERA-Interim-driven COSMO-CLM simulation as verification datasets. Focus is given to the eight European PRUDENCE regions and to lead years 1-5 after initialization. Evidence of the general potential for regional decadal predictability for all three variables is provided. For example, the initialized hindcasts outperform the uninitialized historical runs for some key regions in Europe, particularly in southern Europe. However, forecast skill is not detected in all cases, but it depends on the variable, the region, and the hindcast generation. A comparison of the downscaled hindcasts with the global MPI-ESM-LR runs reveals that the MiKlip prediction system may distinctly benefit from regionalization, in particular for parts of southern Europe and for Scandinavia. The forecast accuracy of the MiKlip ensemble is systematically enhanced when the ensemble size is increased stepwise, and 10 members is found to be suitable for decadal predictions. This result is valid for all variables and European regions in both the global and regional MiKlip ensemble. The present results are encouraging for the development of a regional decadal prediction system.
\end{abstract}




\section{Introduction}

In recent years, interest in climate predictions on timescales from 1 year up to a decade has increased in the climate science community, since this time span falls within the planning horizon for a wide variety of decision makers (Meehl et al., 2009, 2014). A large ensemble of initialized decadal hindcasts has been consolidated in a component of the Coupled Model Intercomparison Project Phase 5 (CMIP5; Taylor et al., 2012), and the number of studies aiming at decadal predictions has strongly increased in recent years (for a review see Meehl et al., 2014). Typically, the North Atlantic is a key region for decadal predictions and forecast skill is found for various quantities such as heat content and sea surface temperature (e.g. Kröger et al., 2012; Yeager et al., 2012), $\mathrm{CO}_{2}$ uptake (Li et al., 2016), and integrated quantities such as the sub-polar gyre (Matei et al., 2012; Yeager et al., 2012; Robson et al., 2013). Recent studies suggest that in particular the Atlantic multi-decadal variability, which is strongly linked to the Atlantic Meridional Overturning Circulation (AMOC), is a major source of decadal predictability (Smith et al., 2012; Pohlmann et al., 2013a). As such low-frequency variability patterns may affect the climate globally, perennial means of meteorological parameters might be predictable several years ahead. Numerous studies focus on primary meteorological parameters on the global scale, in particular surface temperature (e.g. Chikamoto et al., 2012; Doblas-Reyes et al., 2013; Ho et al., 2013; Corti et al., 2015). Comparatively few studies analyse storm tracks (Kruschke et al., 2014, 2016), Atlantic tropical cyclones (Dunestone et al., 2011), intense or extreme events (e.g. Benestad and Mezghani, 2015; Eade et al., 2012), or zoom into a certain region of the world (e.g. Guemas et al., 2015).

In the German research consortium MiKlip (http://www. fona-miklip.de, last access: December 2018), a global decadal prediction system was developed based on the Max Planck Institute Earth system Model (MPI-ESM; for an overview see Marotzke et al., 2016). Within the project, several hindcast generations were produced. The first two are discussed in this paper. The skill of the MiKlip System for decadal predictions was analysed in a wide variety of recent studies. For example, Müller et al. (2012) investigated global surface air temperature in the first generation of the global MiKlip system (baseline0, which was a contribution to CMIP5) and found that the initialized hindcasts have predictive skill over the North Atlantic region, while negative skill scores are identified for the tropics. A modified initialization in the second global MiKlip system generation (baseline1) considerably improves the performance in the tropics, but brings only limited skill improvement over the North Atlantic and Europe (Pohlmann et al., 2013b). Kruschke et al. (2014) identified significant positive skill scores for cyclone frequency over the central North Atlantic in the global baseline0 and baseline1 generations, while no significant skill was detected over the eastern North Atlantic and Europe. Further- more, Kadow et al. (2015) evaluated the global MiKlip system with respect to temperature and precipitation, giving evidence that an enlargement of the hindcast ensemble generally leads to an improvement of the prediction system.

The MiKlip consortium is to our best knowledge the first institution worldwide which has established a decadal prediction system for the regional scale. With this aim, considerable efforts were made to downscale the global MPIESM hindcasts by developing and/or employing different regionalization techniques. After the second project phase, an exceptionally large ensemble was regionalized by dynamical downscaling with regional climate models. Although being computationally expensive, dynamical downscaling has many advantages compared to other downscaling methods. For example, all output variables are physically consistent in dynamically downscaled model runs, which is particularly important when using decadal predictions for impact modelling, hydrological simulations, or user-oriented parameters. Previous experiences reveal that a skill for regional decadal predictions exists but that the interpretation of the results is quite complex due to the non-linear relationship to the global prediction skill. For example, Mieruch et al. (2014) found rather heterogeneous predictive skill for precipitation and temperature over Europe in the baseline 0 generation. The skill differs over space, season, variable, and lead time after initialization. However, a general feature is an improved model spread for precipitation in the downscaled hindcasts when compared to their global counterparts. A potential for predicting regional peak winds and wind energy potentials over central Europe several years ahead was identified in Haas et al. (2016) and Moemken et al. (2016). Specifically, they found highest skill scores for the first years after initialization. All the individual studies analysing the MiKlip prediction system consider different ensembles, variables, lead times, skill metrics, and/or downscaling and data preprocessing methods. Therefore, it is difficult to draw general conclusions regarding skill over Europe in the MiKlip decadal prediction system. In particular, an overall statement for the benefit of regionalization and thus for the prospects of a regional decadal prediction system is hardly possible so far. This motivated us to analyse both the global and the downscaled MiKlip ensemble with respect to different issues.

In this study, the decadal predictive skill for temperature, precipitation, and wind speed over Europe is analysed for the baseline 0 and baseline 1 generations of the MiKlip system. With this aim, we used the same methodologies for all three variables to ensure comparability. Global MPI-ESM and downscaled hindcast ensembles are considered to address the following four key questions:

- Is there a potential for skilful regional decadal predictions in Europe?

- Does regional downscaling provide an added value for decadal predictions? 
- How does the regional decadal predictive skill depend on the ensemble size?

- How does the number of initializations affect the skill estimates?

The datasets used in this study are described in Sect. 2, followed by the methodologies for data pre-processing and skill analysis in Sect. 3. The results for the four key questions are shown in Sect. 4. A summary and discussion, as well as an outlook for future work, are given in Sect. 5.

\section{Data}

The analysed global hindcasts were simulated with the coupled model MPI-ESM in low resolution (MPI-ESM-LR; Giorgetta et al., 2013). Its atmospheric component is based on the ECHAM6 model (Stevens et al., 2013) with a horizontal resolution of T63 and 47 vertical levels, which is coupled to the MPI-OM (Jungclaus et al., 2013) with a horizontal resolution of $1.5^{\circ}$ and 40 vertical levels. Two hindcast generations are considered here, both computed with the MPI-ESM-LR but with different initialization strategies. The first generation (baseline0; Müller et al., 2012; Matei et al., 2012 ) is initialized with oceanic conditions from an experiment where surface fluxes from the NCEP/NOAA reanalysis (Kalnay et al., 1996) were assimilated into the ocean model MPI-OM. The anomalies of ocean temperature and salinity from this experiment were then used to initialize the decadal hindcasts in the coupled model. For the second generation (baseline1; Pohlmann et al., 2013b), temperature and salinity anomalies from the ocean reanalysis system 4 (ORAS4; Balmaseda et al., 2013) are used instead, together with a fullfield 3-D atmospheric initialization using fields from ERA40 (Uppala et al., 2005) and ERA-Interim (Dee et al., 2011). For both generations, yearly initialized hindcasts are available, each of them comprising a 10-year period. For each starting date, an ensemble was generated using a 1-day lagged initialization from the assimilation experiments (cf. Marotzke et al., 2016 for more details). For baseline 0 there are $10 \mathrm{mem}$ bers for each fifth year and 3 members for the other years, whereas baseline 1 provides 10 members for each starting year. Here, we use hindcasts of five starting dates (1 January 1961, 1971, 1981, 1991, and 2001; hereafter referred to as dec1960, dec1970, dec1980, dec1990, and dec2000) to cover the whole period from 1961 to 2010 . This resulted in an ensemble of 50 global hindcasts per generation (baseline 0 and baseline1; hereafter MPI_b0 and MPI_b1).

The global hindcasts are dynamically downscaled to the EURO-CORDEX domain (Giorgi et al., 2009; cf. Fig. 1) at a horizontal grid resolution of $0.22^{\circ}$ using the mesoscale nonhydrostatic regional climate model COSMO-CLM (CCLM; Rockel et al., 2008) on a rotated grid. The model version COSMO4.8-clm17 is employed. By using the MPIESM-LR ensemble as driving data, the global "initial con-

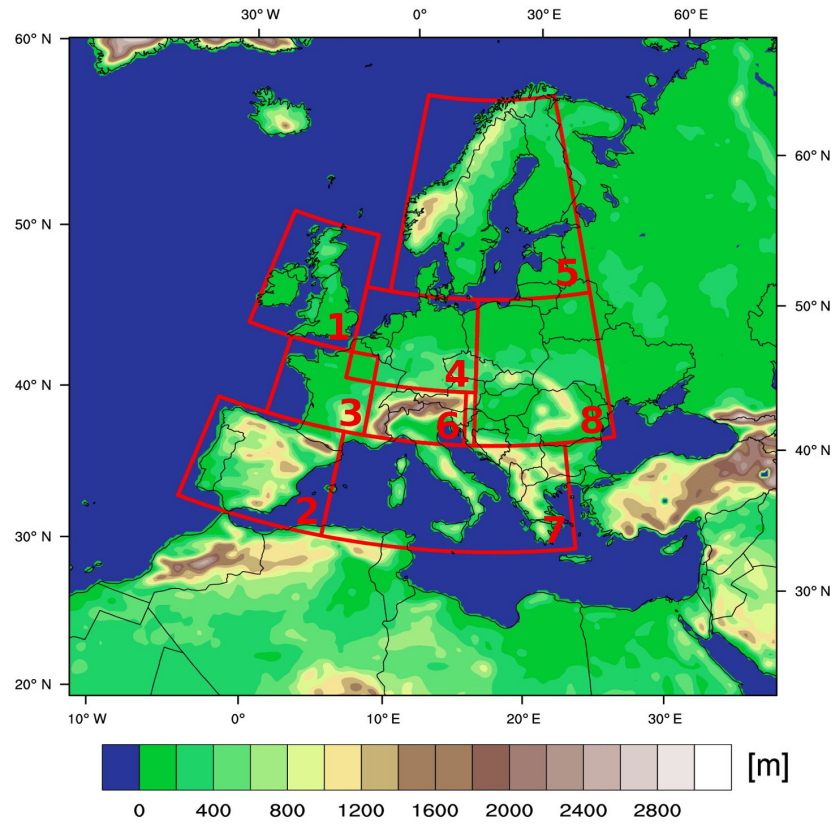

Figure 1. CCLM modelling domain (EURO-CORDEX domain): Model orography and PRUDENCE regions. 1: British Isles, BI; 2: Iberian Peninsula, IP; 3: France, FR; 4: Mid-Europe, ME; 5: Scandinavia, SC; 6: Alps, AL; 7: Mediterranean, MD; and 8: eastern Europe, EA.

dition" perturbation strategy is simply passed to the regional model. Hence, the downscaled hindcasts also inherit the applied anomaly initialization of the global ensembles. The downscaling experiment includes hindcasts for dec1960, dec1970, dec1980, dec1990, and dec2000, with 10 members per decade (hereafter CCLM_b0 and CCLM_b1). The regional ensembles therefore consist of the same time series like the global ensembles MPI_b0 and MPI_b1.

We evaluate the performance of both the global MPIESM and the regional CCLM hindcasts with the following datasets. For temperature and precipitation, we consider the observational dataset E-OBS (Haylock et al., 2008) based on the ECA \& D (European Climate Assessment \& Dataset; http://ecad.eu/, last access: September 2016) at a regular $0.25^{\circ} \times 0.25^{\circ}$ grid. As no gridded dataset is available for wind, a CCLM simulation forced with boundary conditions from ERA40 and ERA-Interim is employed as verification dataset for wind speed. For this reanalysis-driven simulation, CCLM is applied in the same model set-up as for the regionalization of the global hindcast ensemble (see above).

In this study, we want to quantify if the initialization with observed climate states improves the performance of decadal predictions. To address this issue, uninitialized historical CMIP5 runs are usually considered as reference dataset (see also Sect. 3.2). With this aim, a 10-member ensemble of uninitialized MPI-ESM-LR historical runs started from a pre-industrial control simulation are used, which use ob- 
served natural and anthropogenic forcings (e.g. aerosol and greenhouse gas concentrations among others) for the period 1850-2005 (e.g. Müller et al., 2012).

\section{Methods}

\subsection{Data processing}

All datasets considered in this study are pre-processed in an analogous manner to enable a direct comparison. First, all data are bilinear interpolated to the grid used for the E-OBS data $\left(0.25^{\circ} \times 0.25^{\circ}\right.$ resolution $)$. At each grid point, monthly anomaly time series are computed by subtracting the longterm means for the period 1961-2010 from the interpolated raw datasets. Finally, annual values are derived and multiannual means for lead years 1-5 are built for further evaluation.

Following the suggestion of Goddard et al. (2013), the skill analysis is partly performed for spatial means. Spatial averaging of the anomaly time series is performed for eight PRUDENCE regions over Europe (see Fig. 1; Christensen and Christensen, 2007). Note that we only used grid points over land surfaces for the spatial means as E-OBS data are not available over the oceans. Additionally, we calculated the predictive skill on the basis of all individual grid points for specific analysis.

\subsection{Skill metrics}

The following metrics are used to evaluate the performance of the global and regional hindcast ensembles and to address the four key questions: the mean squared error skill score (MSESS) and the anomaly correlation coefficient (ACC), which are both measures for the forecast accuracy. The skill metrics are applied to the pre-processed time series described in Sect. 3.1 and are computed for multiannual means for lead time years 1-5 after initialization. Recent studies analysing the MiKlip decadal prediction system demonstrated that the MiKlip ensemble performs best for the first years after initialization for a wide range of variables, while the skill diminishes for longer forecast periods. For example, Müller et al. (2012) found highest skill scores for years 1-4 and 2-5 for annual mean surface temperature for both the North Atlantic region and global means. The same is true for annual wind speed and wind energy potentials over central Europe, for which skilful predictions are mainly restricted to the first years after initialization (years 1-4), while negative skill scores are found for longer lead time periods (Moemken et al., 2016). Kruschke et al. (2014) provided evidence that the prediction skill for winter cyclones over the North Atlantic region is best for years 2-5 and reduced for longer time periods. Following the recommendation by Goddard et al. (2013), we focus, in the following, on the lead time years $1-5$ after initialization.
The deterministic MSESS (Murphy, 1988) is defined as

$\operatorname{MSESS}(\mathrm{HRO})=1-\frac{\mathrm{MSE}_{\text {hind }}}{\mathrm{MSE}_{\mathrm{ref}}}$

with

$\mathrm{MSE}_{\text {hind }}=\frac{1}{N} \sum_{i=1}^{N}\left(\overline{H_{i}}-O_{i}\right)^{2}$ and

$\mathrm{MSE}_{\mathrm{ref}}=\frac{1}{N} \sum_{i=1}^{N}\left(\overline{R_{i}}-O_{i}\right)^{2}$,

where $i=1, \ldots, N$ is the time index, $\mathrm{MSE}_{\text {hind }}$ is the mean squared error (MSE) between the ensemble mean of the dynamical downscaled hindcasts $\left(H_{i}\right)$ and the verification data $\left(O_{i}\right)$, and $\mathrm{MSE}_{\mathrm{ref}}$ is the mean squared error of a reference dataset $\left(R_{i}\right)$. In this study, the uninitialized historical simulations, the climatology, or the global initialized hindcasts are used as reference. A MSESS could be between minus infinity and one, with positive MSESS meaning that the hindcasts are closer to the verification dataset than the reference, indicating that the initialization and downscaling lead to higher accuracy in predicting observed values.

Following Murphy (1988) and given that anomalies are used (as in this study), the MSESS with the climatology as reference (i.e. $R_{i} \equiv \bar{O}$ ) can be decomposed as follows:

$\operatorname{MSESS}(H, \bar{O}, O)=r_{\mathrm{H}, \mathrm{O}}^{2}-\left(r_{\mathrm{H}, \mathrm{O}}-\frac{S_{\mathrm{H}}}{S_{\mathrm{O}}}\right)^{2}$,

where $r_{\mathrm{H}, \mathrm{O}}$ is the correlation between the hindcasts $\left(H_{i}\right)$ and the verification data $\left(O_{i}\right)$, and $S_{\mathrm{H}}$ and $S_{\mathrm{O}}$ are the sample variances of the simulation ensembles and the observations, respectively. The second term is the conditional bias.

$\mathrm{CB}=\left(r_{\mathrm{H}, \mathrm{O}}-\frac{S_{\mathrm{H}}}{S_{\mathrm{O}}}\right)$.

In the case that another reference is applied, the decomposition is as follows:

$\operatorname{MSESS}(H, R, O)=$

$$
\frac{r_{\mathrm{H}, \mathrm{O}}^{2}-\left[r_{\mathrm{H}, \mathrm{O}}-\frac{S_{\mathrm{H}}}{S_{\mathrm{O}}}\right]^{2}-r_{\mathrm{R}, \mathrm{O}}^{2}+\left[r_{\mathrm{R}, \mathrm{O}}-\frac{S_{\mathrm{R}}}{S_{\mathrm{O}}}\right]^{2}}{1-r_{\mathrm{R}, \mathrm{O}}^{2}+\left[r_{\mathrm{R}, \mathrm{O}}-\frac{S_{\mathrm{R}}}{S_{\mathrm{O}}}\right]^{2}}
$$

or

$\operatorname{MSESS}(H, R, O)=$

$$
\frac{\operatorname{MSESS}(H, \bar{O}, O)-\operatorname{MSESS}(R, \bar{O}, O)}{1-\operatorname{MSESS}(R, \bar{O}, O)},
$$

where $\operatorname{MSESS}(H, R, O)$ denotes the skill score of a hindcast $H$ to a reference $R$ given the observations $O$. $\operatorname{MSESS}(H, \bar{O}, O)$ and $\operatorname{MSESS}(R, \bar{O}, O)$ are the respective skill scores against the climatology. 
Hence, MSESS depends on the conditional bias, as well as on the correlation. It is smaller than the correlation in the case that there is a conditional bias, for which the optimal value is 0 . CB depends on the balance between correlation and the ratio of the standard deviation between the ensemble and the observation. The improvement or added value of $\mathrm{CB}$ is calculated according to Kadow et al. (2015) as

$\mathrm{CB}_{\mathrm{AV}}=\left|r_{\text {ref,obs }}-\left(\frac{S_{\text {ref }}}{S_{\mathrm{O}}}\right)\right|-\left|r_{\text {hind,obs }}-\left(\frac{S_{\text {hind }}}{S_{\mathrm{O}}}\right)\right|$.

The correlation or ACC (anomaly correlation coefficient; e.g. Wilks, 2011) is computed as the Pearson correlation between the ensemble mean of the hindcasts at a certain location $i$ and the corresponding observations (Obs):

$\mathrm{ACC}_{i}=\frac{1}{N} \frac{\sum_{t} H_{t} O_{t}}{S_{\mathrm{H}} S_{\mathrm{O}}}$,

where $t=1, \ldots, N$ is the time index. The ACC quantifies the accuracy of the predictions only in terms of the temporal course, while it is independent from the variance of the target variable and from the mean bias. To compare the performance of the hindcasts and of the uninitialized historical runs, we compute the difference of the ACC of the hindcasts minus the ACC of the historical runs for several issues (hereafter delta_ACC).

The significance of the skill scores is determined by using a bootstrapping approach at the $95 \%$ level (Kadow et al., 2015) and a $t$ test of the respective distributions.

\section{Results}

\subsection{Is there a potential for skilful regional decadal predictions in Europe?}

In this section, we address the first key question and analyse the general potential for skilful regional decadal predictions over Europe. Figure 2 shows MSESS plots for temperature, precipitation, and surface wind speed in CCLM_b0 and CCLM_b1 with the climatology as reference. Not surprisingly, the MSESS is positive for most of Europe for temperature. It is significant for most regions in western Europe in CCLM_b0 and large parts of southern Europe in CCLM_b1 (Fig. 2a and b). This is due to the strong positive trend in the observed temperature, which is predicted by the hindcasts but not captured by the climatology. Deviations between both ensembles are larger for precipitation (Fig. 2c and d), where the MSESS fields are distinctly patchier when compared to temperature (Fig. 2a and b). While positive and significant skill scores are found over large parts of western Europe in CCLM_b1 (Fig. 2d), MSESS values are mostly negative over this region in CCLM_b0 (Fig. 2c). For wind speed (Fig. 2e and $\mathrm{f}$ ), a positive MSESS is found only for northern Europe and CCLM_b0, where skill scores are often significant. As at the same time negative skill scores are found for other European regions in both ensembles, the climatology is generally closer to the observations than the hindcasts. In this respect, we have analysed the respective spatial mean wind speed time series for the Iberian Peninsula (Prudence region 2) and CCLM_b0. The wind speed shows a slight negative trend in CCLM_b0, while the trend is slightly positive for the observational dataset (not shown). At the same time, the decadal variability for wind speed is quite small over this region in all datasets (it ranges from 0.02 to -0.02 in CCLM_b0 and E-OBS). Hence, the deviation of the climatology from the observations, and thus its MSE, is generally small in this region, resulting in a negative MSESS when using the climatology as reference (see also Eq. 3 for MSESS in Sect. 3.2).

A different picture is revealed when using the uninitialized historical runs as reference dataset for the MSESS computation (Fig. 3). For temperature (Fig. 3a and b), positive skill scores are found in both ensembles over Scandinavia and for southeastern Europe, and at some grid points this prediction skill is significant. A stripe of negative values occurs over the British Isles and central Europe. The analysis of the time series for Mid-Europe (spatial mean over Prudence region 4) reveals that this negative skill mainly results from a strong temperature increase from dec1960 to dec1970 in the observations, while CCLM_b0 and CCLM_b1 depict a decrease in temperature (not shown), which in fact was observed in southern Europe for instance. As a consequence, the temperature in the hindcasts has larger deviations than the uninitialized simulations compared to the observations during the first half of the considered period, but agree well to the observations from dec1980 onwards. The largest deviations between CCLM_b0 and CCLM_b1 are found for Iberia, parts of southern France, and Italy, where the MSESS is positive for CCLM_b1 but neutral to negative for CCLM_b0.

Again, deviations in the MSESS fields between both ensembles are larger for precipitation (Fig. 3c and d), reflecting the local character of rainfall. Both ensembles show positive and partly significant MSESS values for regions in Scandinavia and eastern Europe, and to a lesser extent for Iberia and the British Isles (Fig. 3c and d). In CCLM_b1, predictive skill is also identified over western central Europe. Thus for CCLM_b1 positive skill is found for larger areas indicating an added value of the improved initialization procedure in baseline 1 compared to baseline 0 .

Regarding wind speed, the predictive skill in CCLM_b0 (Fig. 3e) shows high and significant MSESS values over Scandinavia, Iberia, southern Italy, and along the coasts of the North Sea and Baltic Sea, while negative values are found, for example, over parts of France, southern Germany, and the Alpine region. In CCLM_b1, the MSESS depicts positive values over most of western and central Europe, while negative values are now identified along the eastern coast of the Baltic Sea (Fig. 3f). Overall the predictive skill of CCLM_b0 is slightly higher and affects a larger area, in- 

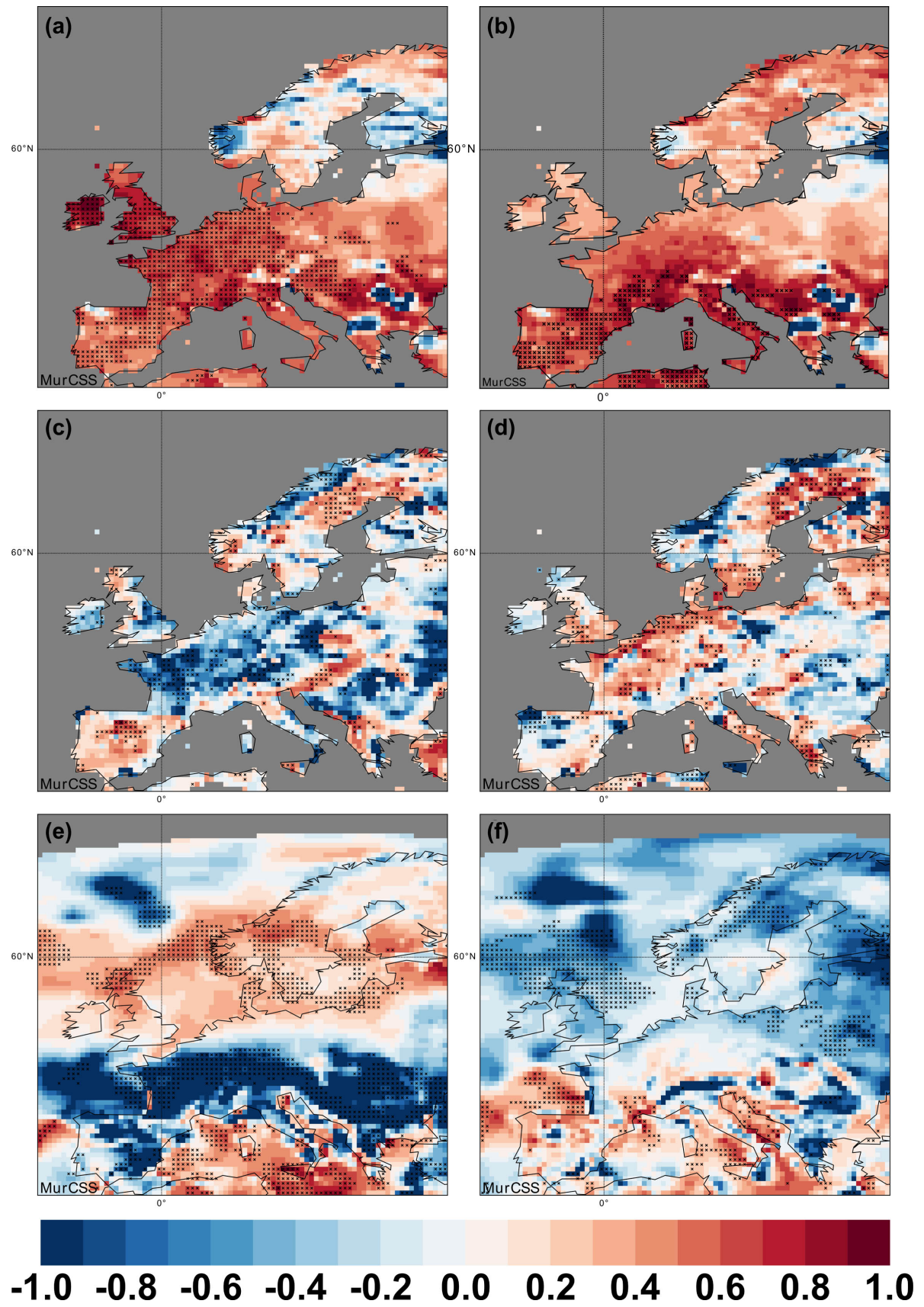

Figure 2. Spatial distribution of the MSESS for the multi-annual mean anomalies of lead years 1-5 for (a) temperature in CCLM_b0, (b) temperature in CCLM_b1, (c) precipitation in CCLM_b0, (d) precipitation in CCLM_b1, (e) wind speed in CCLM_b0, and (f) wind speed in CCLM_b1. As reference dataset we have used the climatology. The black dots indicate significant skill at the $95 \%$ level (bootstrapping).

dicating that the changes in the initialization method do not improve the results for wind speed.

We conclude that in terms of the MSESS accuracy there generally is a potential for skilful decadal predictions over Europe in the regional MiKlip ensembles. However, the skill pattern depends on the region and the variable. For individual regions, the initialization leads to an added value for accurate (retrospective) forecasts several years ahead, while for some regions the uninitialized historical runs deliver better predictions. Also the discrepancies between the two hindcast generations (CCLM_b0 and CCLM_b1) are rather heterogeneous. While for temperature we only found a slight shift in the pattern due to the different initialization methods, discrepancies can be large for precipitation and wind speed depending on the region. 

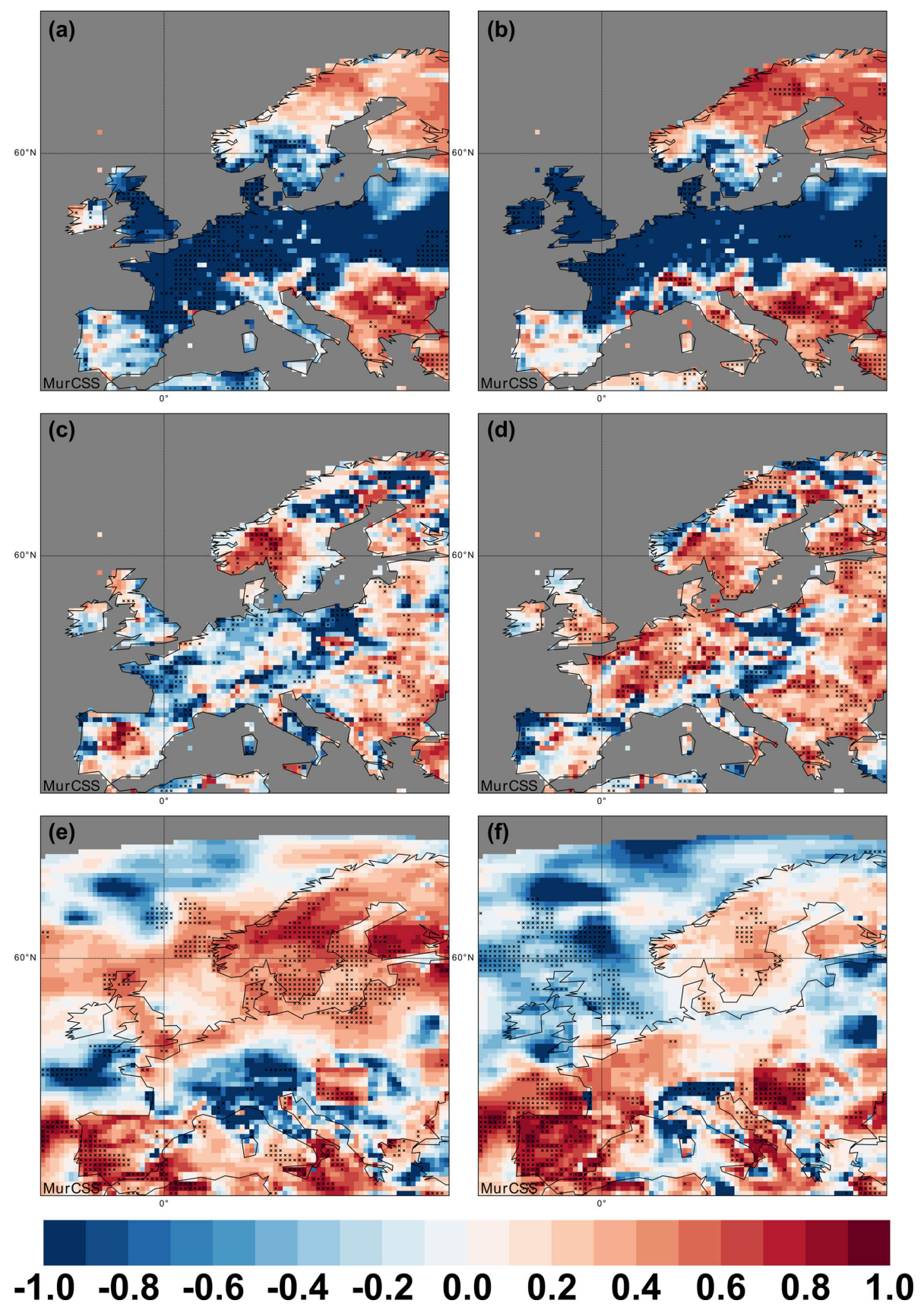

Figure 3. Spatial distribution of the MSESS for the multi-annual mean anomalies of lead years 1-5 for (a) temperature in CCLM_b0, (b) temperature in CCLM_b1, (c) precipitation in CCLM_b0, (d) precipitation in CCLM_b1, (e) wind speed in CCLM_b0, and (f) wind speed in CCLM_b1. As reference dataset we have used the uninitialized historical ensemble. The black dots indicate significant skill at the $95 \%$ level (bootstrapping).

\subsection{Does regional downscaling provide an added value for decadal predictions?}

Recent studies document that the application of regional climate models may improve climate simulations, in particular over complex terrain (Berg et al., 2013; Feldmann et al., 2013; Hackenbruch et al., 2016). This is mainly due to a more realistic representation of the topography (e.g. moun- tain ranges or coastlines) in the regional climate models (RCMs) compared to global-scale general circulation models (GCMs). In this section, we analyse whether the downscaling with a regional climate model also leads to an added value for decadal predictions over Europe. With this aim, we use MPI_b0 and MPI_b1 as reference datasets for the MSESS shown in Fig. 4 (see also Sect. 3.2). 

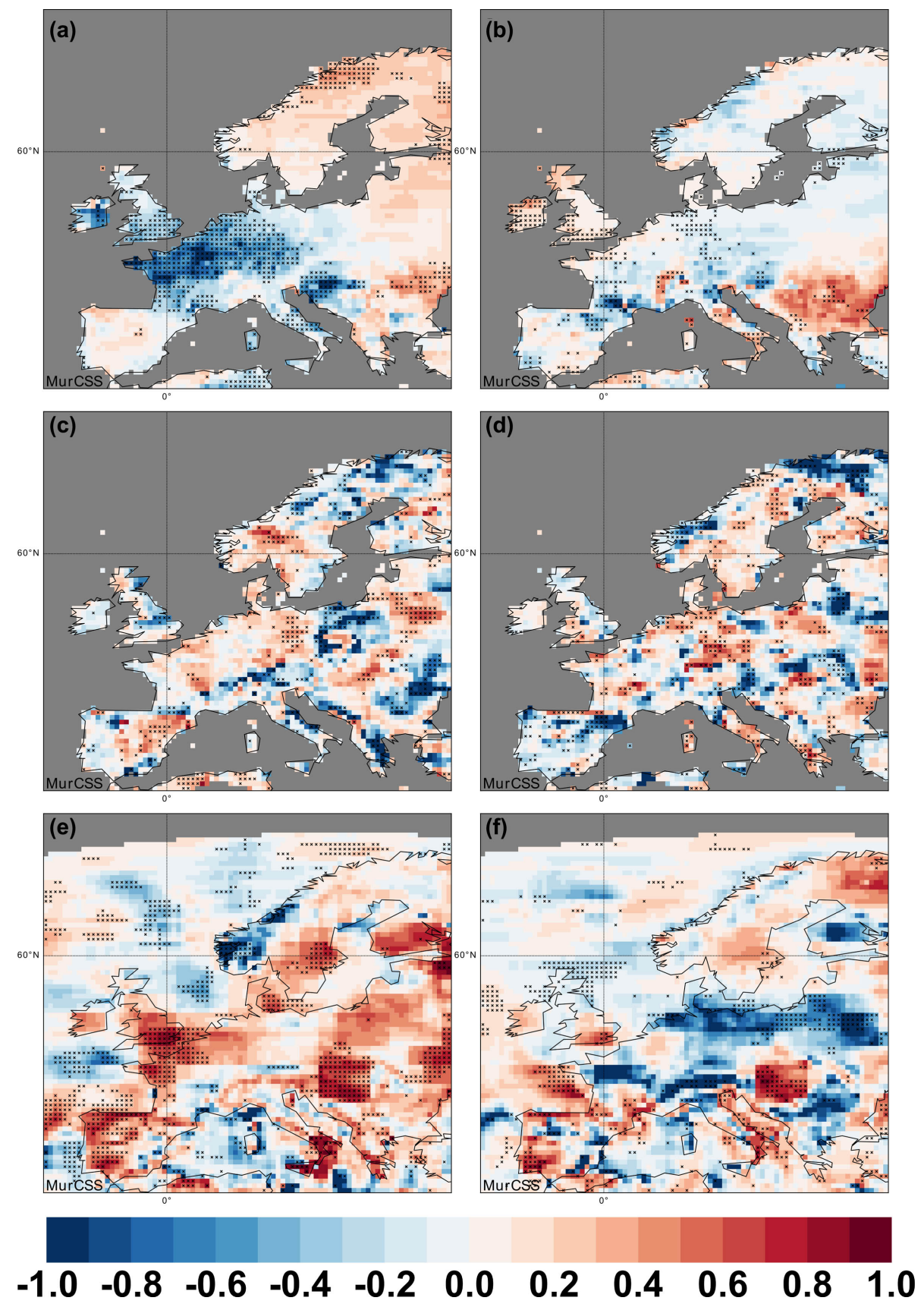

Figure 4. Spatial distribution of the MSESS for the multi-annual mean anomalies of lead years 1-5 for (a) temperature in CCLM_b0, (b) temperature in CCLM_b1, (c) precipitation in CCLM_b0, (d) precipitation in CCLM_b1, (e) wind speed in CCLM_b0, and (f) wind speed in CCLM_b1. As reference dataset we have used the respective global MPI data. The black dots indicate significant skill at the $95 \%$ level (bootstrapping).

Generally, significant improvements in the prediction skill by dynamical downscaling are restricted to limited geographical areas, and they strongly depend on the variable. For temperature a significant added value of downscaling is found over Scandinavia and southeast Europe in CCLM_b0, and over southeast Europe and the British Isles in CCLM_b1 (Fig. 4a and b). Therefore, the regionalization typically pro- vides an improvement in regions where the global hindcasts show mostly medium to lower skill. In some regions with already high skill in the MPI-ESM hindcasts there is no improvement by the downscaling. This includes, for example, an area from the British Isles over France to Germany in baseline 0 and regions along the western Mediterranean coast in baseline1. However, the global model outperforms the re- 
Table 1. MSESS, ACC, and conditional bias (CB) for the CCLM ensembles (left half) and added value compared to the global MPI ensembles (right half) for b0 (upper half) and b1 (lower half) for temperature averaged over the eight Prudence regions (cf. Fig. 1) and the whole of Europe (EU). In the left half, bold (italic) numbers represent MSESS values above +0.3 (below -0.3 ), ACC values above +0.4 (below -0.4 ), and $\mathrm{CB}$ values between \pm 0.2 are marked in bold and beyond \pm 0.3 in italic. In the right half, bold (italic) numbers corresponds to a distinct improvement (deterioration) by dynamical downscaling using a common threshold of \pm 0.05 .

\begin{tabular}{lccccrrrr}
\hline \multirow{2}{*}{$\begin{array}{l}\text { Temp } \\
\text { b0 }\end{array}$} & \multicolumn{3}{c}{ Skill } & & & \multicolumn{3}{c}{ Added value } \\
\cline { 2 - 5 } \cline { 7 - 8 } & MSESS & ACC & CB & & MSESS & ACC & CB \\
\hline BI & $\mathbf{0 . 7 5}$ & $\mathbf{0 . 9 0}$ & $\mathbf{0 . 1 5}$ & & -0.04 & -0.02 & -0.02 \\
FR & $\mathbf{0 . 6 6}$ & $\mathbf{0 . 8 9}$ & 0.34 & & -0.12 & -0.05 & -0.04 \\
ME & $\mathbf{0 . 5 6}$ & $\mathbf{0 . 8 0}$ & 0.23 & & -0.11 & -0.05 & -0.05 \\
AL & $\mathbf{0 . 5 7}$ & $\mathbf{0 . 8 2}$ & $\mathbf{0 . 1 0}$ & & -0.05 & -0.04 & 0.02 \\
IP & $\mathbf{0 . 5 0}$ & $\mathbf{0 . 7 6}$ & 0.22 & & 0.01 & 0.03 & -0.08 \\
MD & $\mathbf{0 . 4 2}$ & $\mathbf{0 . 7 5}$ & $\mathbf{- 0 . 0 4}$ & & 0.01 & -0.02 & $\mathbf{0 . 0 5}$ \\
EA & $\mathbf{0 . 4 5}$ & $\mathbf{0 . 7 2}$ & $\mathbf{- 0 . 1 6}$ & & $\mathbf{0 . 0 5}$ & 0.00 & $\mathbf{0 . 1 1}$ \\
SC & 0.02 & $\mathbf{0 . 4 5}$ & -0.36 & & $\mathbf{0 . 2 0}$ & $\mathbf{0 . 0 7}$ & $\mathbf{0 . 1 6}$ \\
EU & $\mathbf{0 . 3 5}$ & $\mathbf{0 . 6 7}$ & $\mathbf{- 0 . 0 9}$ & & $\mathbf{0 . 0 5}$ & 0.01 & $\mathbf{0 . 0 9}$ \\
\hline Temp & & Skill & & & & Added value & \\
\cline { 2 - 5 } b1 & MSESS & ACC & CB & & MSESS & ACC & CB \\
\hline BI & $\mathbf{0 . 3 4}$ & $\mathbf{0 . 6 4}$ & 0.25 & & $\mathbf{0 . 1 2}$ & $\mathbf{0 . 1 5}$ & -0.07 \\
FR & $\mathbf{0 . 6 3}$ & $\mathbf{0 . 8 7}$ & 0.34 & & -0.03 & -0.01 & -0.01 \\
ME & $\mathbf{0 . 5 1}$ & $\mathbf{0 . 7 5}$ & $\mathbf{0 . 1 9}$ & & -0.03 & -0.02 & -0.02 \\
AL & $\mathbf{0 . 6 8}$ & $\mathbf{0 . 8 9}$ & $\mathbf{0 . 0 4}$ & & -0.03 & -0.01 & $\mathbf{0 . 0 6}$ \\
IP & $\mathbf{0 . 6 2}$ & $\mathbf{0 . 8 3}$ & $\mathbf{0 . 2 0}$ & & -0.01 & 0.01 & -0.03 \\
MD & $\mathbf{0 . 5 2}$ & $\mathbf{0 . 8 2}$ & $\mathbf{- 0 . 0 9}$ & & $\mathbf{0 . 0 8}$ & -0.01 & $\mathbf{0 . 0 7}$ \\
EA & $\mathbf{0 . 3 7}$ & $\mathbf{0 . 6 6}$ & $\mathbf{- 0 . 2 0}$ & & $\mathbf{0 . 0 5}$ & -0.04 & $\mathbf{0 . 1 5}$ \\
SC & 0.24 & $\mathbf{0 . 5 6}$ & $\mathbf{- 0 . 1 8}$ & & -0.03 & -0.03 & -0.09 \\
EU & $\mathbf{0 . 4 0}$ & $\mathbf{0 . 6 9}$ & $\mathbf{- 0 . 0 5}$ & & 0.01 & -0.01 & 0.01 \\
\hline
\end{tabular}

gional model over large parts of northwest Europe in the baseline 0 ensemble (see also Table 1).

Again, rather patchy MSESS fields are obtained for precipitation. Nevertheless, there are several regions with significantly improved prediction skills in the CCLM ensembles compared to MPI_b0 and MPI_b1 (Fig. 4c and d). For example, both CCLM_b0 and CCLM_b1 reveal significant positive MSESS over eastern Germany and over parts of Scandinavia.

The added value of downscaling is most pronounced for wind in CCLM_b0 (Fig. 4e). Significant improvements of the MSESS are detected for southeast Europe, Italy, Scandinavia, and for coastal areas of Iberia, France, and England. Areas with an added value of downscaling are also existent in CCLM_b1 (Fig. 4f), but visibly reduced compared to CCLM_b0.

In Tables 1-3 we summarize the analysis of skill (cf. Fig. 2) and added value (cf. Fig. 4) of the regional hindcasts compared to the climatology for the three variables as spatial means over the PRUDENCE regions (cf. Fig. 1). The tables display the MSESS as well as its components correla-
Table 2. As Table 1, but for precipitation.

\begin{tabular}{|c|c|c|c|c|c|c|}
\hline \multirow{2}{*}{$\begin{array}{l}\text { Prec } \\
\text { b0 }\end{array}$} & \multicolumn{3}{|c|}{ Skill } & \multicolumn{3}{|c|}{ Added value } \\
\hline & MSESS & ACC & CB & MSESS & ACC & CB \\
\hline BI & -0.17 & -0.04 & -0.39 & -0.09 & -0.09 & -0.13 \\
\hline FR & -0.64 & -0.55 & -0.87 & 0.07 & 0.09 & 0.01 \\
\hline ME & -0.49 & -0.31 & -0.72 & 0.18 & 0.26 & 0.18 \\
\hline AL & -0.27 & -0.10 & -0.46 & -0.14 & -0.04 & -0.19 \\
\hline IP & 0.12 & 0.41 & 0.06 & 0.05 & 0.17 & 0.12 \\
\hline MD & -0.08 & 0.20 & -0.25 & -0.13 & -0.07 & -0.16 \\
\hline EA & -0.28 & 0.02 & -0.45 & -0.05 & -0.09 & -0.05 \\
\hline SC & -0.06 & 0.16 & -0.27 & 0.02 & -0.01 & 0.05 \\
\hline EU & -0.17 & 0.06 & -0.35 & 0.00 & 0.01 & 0.01 \\
\hline Prec & \multicolumn{3}{|c|}{ Skill } & \multicolumn{3}{|c|}{ Added value } \\
\hline b1 & MSESS & ACC & $\mathrm{CB}$ & MSESS & ACC & $\mathrm{CB}$ \\
\hline BI & 0.07 & 0.21 & -0.04 & 0.01 & 0.01 & -0.01 \\
\hline FR & 0.21 & 0.51 & -0.04 & 0.04 & 0.05 & -0.02 \\
\hline ME & 0.20 & 0.54 & 0.01 & 0.16 & 0.20 & 0.01 \\
\hline AL & -0.01 & 0.19 & -0.11 & -0.06 & -0.05 & -0.11 \\
\hline IP & -0.09 & 0.12 & -0.20 & -0.15 & -0.13 & -0.16 \\
\hline MD & 0.05 & 0.29 & -0.13 & 0.03 & 0.03 & -0.02 \\
\hline EA & -0.11 & 0.05 & -0.32 & 0.05 & -0.01 & 0.03 \\
\hline $\mathrm{SC}$ & 0.06 & 0.41 & -0.17 & 0.00 & 0.05 & 0.04 \\
\hline EU & 0.03 & 0.28 & -0.16 & 0.02 & 0.02 & 0.00 \\
\hline
\end{tabular}

Table 3. As Table 1, but for wind speed.

\begin{tabular}{|c|c|c|c|c|c|c|}
\hline \multirow{2}{*}{$\begin{array}{l}\text { Wind } \\
\text { b0 }\end{array}$} & \multicolumn{3}{|c|}{ Skill } & \multicolumn{3}{|c|}{ Added value } \\
\hline & MSESS & $\mathrm{ACC}$ & $\mathrm{CB}$ & MSESS & $\mathrm{ACC}$ & $\mathrm{CB}$ \\
\hline BI & 0.21 & 0.50 & 0.19 & 0.23 & 0.09 & -0.12 \\
\hline FR & -0.77 & -0.63 & -0.88 & 0.09 & -0.04 & 0.06 \\
\hline ME & -0.22 & -0.04 & -0.34 & 0.23 & 0.13 & 0.23 \\
\hline $\mathrm{AL}$ & -0.69 & -0.45 & -0.81 & 0.07 & 0.06 & 0.03 \\
\hline IP & -0.36 & -0.08 & -0.52 & 0.26 & 0.17 & 0.18 \\
\hline MD & 0.06 & 0.38 & -0.10 & 0.12 & 0.02 & 0.18 \\
\hline EA & -0.46 & -0.21 & -0.59 & 0.36 & 0.10 & 0.31 \\
\hline $\mathrm{SC}$ & 0.19 & 0.50 & $\mathbf{0 . 1 7}$ & 0.16 & 0.09 & 0.02 \\
\hline EU & -0.11 & 0.16 & -0.20 & 0.15 & 0.07 & 0.21 \\
\hline Wind & \multicolumn{3}{|c|}{ Skill } & \multicolumn{3}{|c|}{ Added value } \\
\hline b1 & MSESS & $\mathrm{ACC}$ & $\mathrm{CB}$ & MSESS & $\mathrm{ACC}$ & $\mathrm{CB}$ \\
\hline BI & -0.35 & -0.57 & -0.80 & 0.02 & -0.09 & -0.01 \\
\hline FR & -0.01 & 0.28 & -0.22 & 0.00 & 0.07 & -0.05 \\
\hline ME & -0.12 & -0.06 & -0.38 & -0.24 & -0.41 & -0.29 \\
\hline $\mathrm{AL}$ & -0.14 & 0.32 & -0.30 & -0.30 & -0.13 & -0.22 \\
\hline IP & 0.05 & 0.29 & -0.17 & 0.19 & 0.21 & 0.18 \\
\hline MD & 0.07 & 0.41 & -0.06 & 0.02 & 0.05 & -0.03 \\
\hline EA & -0.38 & -0.23 & -0.69 & -0.09 & -0.07 & -0.21 \\
\hline $\mathrm{SC}$ & -0.37 & -0.34 & -0.67 & 0.06 & -0.05 & 0.02 \\
\hline EU & -0.23 & -0.11 & -0.50 & 0.00 & -0.02 & -0.04 \\
\hline
\end{tabular}

tion (ACC) and conditional bias (CB), according to the Murphy decomposition (cf. Sect. 3.2). The formatting of the cells in the left half of the tables display distinctly positive (bold numbers), negative (italic numbers), or slightly positive skill (no formatting) derived from the results shown in Fig. 2 for the MSESS. A common threshold for all three variables is 
chosen in a way that above this level a skill score is regarded as significant by the bootstrapping procedure. The thresholds for the formatting are above (bold) or below (italic) \pm 0.3 for the MSESS, and \pm 0.4 for ACC. Since the optimal value for the conditional bias is zero, a low $\mathrm{CB}$ is depicted for the absolute value, $|\mathrm{CB}|$, being below 0.2 (bold), and a high $\mathrm{CB}$ for $|\mathrm{CB}|$ being larger than 0.3 (italic). The formatting for the added value in the right half of the tables corresponds to the sign of the skill difference (dynamical downscaled minus global MPI; bold: distinctly positive; italic: distinctly negative) in a region. The threshold is $5 \%( \pm 0.05)$ and chosen in an analogous way to the left half of the tables.

For temperature (Table 1), the MSESS and ACC are high in all regions except Scandinavia (SC). The correlation is above 0.8 in CCLM_b0 for the northwestern part of Europe - namely the British Isles (BI), France (FR), MidEurope (ME), and the Alps (AL). For CCLM_b1 the highest correlation is found more in the southern part of the region, namely in France (FR), the Iberian Peninsula (IP), the Alps (AL), and the Mediterranean (MD). The CB is low for most areas, except France (FR) and Scandinavia (SC) in CCLM_b0. The MSESS is high due to the high ACC and the low CB. MSESS and ACC are higher and CB lower for b1 than for b0 over the whole of Europe (EU). A significant added value of the regionalization of baseline 0 occurs for Scandinavia (SC) and Eastern Europe (EA) as well as for Europe (EU). In these regions CB is significantly lower for CCLM compared to the MPI-ESM hindcasts. CCLM_b1 shows an added value for the regions British Isles (BI), the Mediterranean (MD) and Eastern Europe (EA) as well as over the entire domain (EU). The main cause is again a reduced conditional bias.

The MSESS for precipitation (Table 2) is much lower than for temperature. It is mostly negative for CCLM_b0 and only slightly positive for some regions in CCLM_b1. For CCLM_b0 a significant positive correlation is only found for the Iberian Peninsula (IP). The CB is generally negative (except for IP), which is inherited from the global hindcasts, since for MPI_b0 CB is even lower than for CCLM_b0. Over the whole domain the added value is low and not significant. For CCLM_b1, a positive ACC is uncovered for France (FR), Mid-Europe (ME) and Scandinavia (SC). The conditional bias is much lower than for CCLM_b0 and only slightly negative in most areas. An added value in relation to MPI_b1 occurs in those regions where ACC of CCLM_b1 is positive. There is also an added value for the whole domain (EU), but it is only significant for ACC.

The highest ACC for the $10 \mathrm{~m}$ wind speed is revealed for northern Europe (BI and SC) as well as in the Mediterranean (MD) for CCLM_b0, and in the southern regions for CCLM_b1 (Table 3). These are all regions with low to moderate conditional bias. CB is strongly negative in regions with a low skill. Interestingly, the added value for the MSESS of CCLM_b0 is significant in all regions, and for most regions a significant improvement is also visible with respect to ACC and CB. For CCLM_b1, on the other hand, significant improvements of MSESS and ACC compared to MPI_b1 are only found for a few regions.

We conclude that regional downscaling may indeed provide an added value for decadal predictions over Europe, both for individual grid points as well as for spatial means. However, this added value is not systematic but depends on variable and region.

\subsection{How does the regional decadal predictive skill depend on the ensemble size?}

Past studies suggest that the ensemble size of a prediction system has an impact on the forecast skill of a model (Richardson, 2001; Ferro et al., 2008). Generally, there is a consensus that the prediction skill for both seasonal and decadal predictions is enhanced when the number of ensemble members is increased. Kadow et al. (2015) analysed the global MiKlip baseline1 generation and concluded that the forecast accuracy for surface temperature for lead years 1 and 2-9 is improved for nearly the whole globe when the ensemble size is increased from 3 to 10 members. This is in line with the findings of Sienz et al. (2016) who examined the prediction skill for North Atlantic sea surface temperatures in the same hindcast ensemble. Also for seasonal predictions of the North Atlantic Oscillation a forecast system profits from increasing size (e.g. Scaife et al., 2014). However, the ensemble-size-dependent skill bias has never been demonstrated based on regional decadal climate predictions before. With this aim, we analyse the impact of the ensemble size on the predictive skill for the eight PRUDENCE regions in Europe in both the regional and the global MiKlip ensembles. In the following, results are only shown for the Iberian Peninsula (IP), as the findings are similar for the other PRUDENCE regions. Figure 5 exhibits the dependency of MSESS and delta_ACC when compared to the historical simulations for lead years 1-5 ( $y$ axis) on the ensemble size ( $x$ axis) for all three variables spatially averaged over IP. For each ensemble size $n$ ( $n$ varying between 2 and 10), the solid coloured lines depict the averaged skill scores for all permutations of $n$-member ensemble combinations for each of the four individual hindcast ensembles (MPI_b0, MPI_b1, CCLM_b0, and CCLM_b1). Note that for the reference dataset always the full ensemble of $10 \mathrm{mem}-$ bers of the uninitialized historical runs is used, independently of the ensemble size of the initialized hindcasts.

As expected, enhanced predictive skill can be observed when the number of members is increased stepwise for both the global and the regional hindcast ensembles. MSESS shows a rather logarithmic relationship with increasing $n$, depicting the highest skill scores for the 10 member ensembles for all three variables (Fig. 5a-c). On the other hand, the lowest skill scores are always found for the 2-member ensembles. This ensemble size dependency of MSESS is systematic and is detected in both hindcast generations for all 

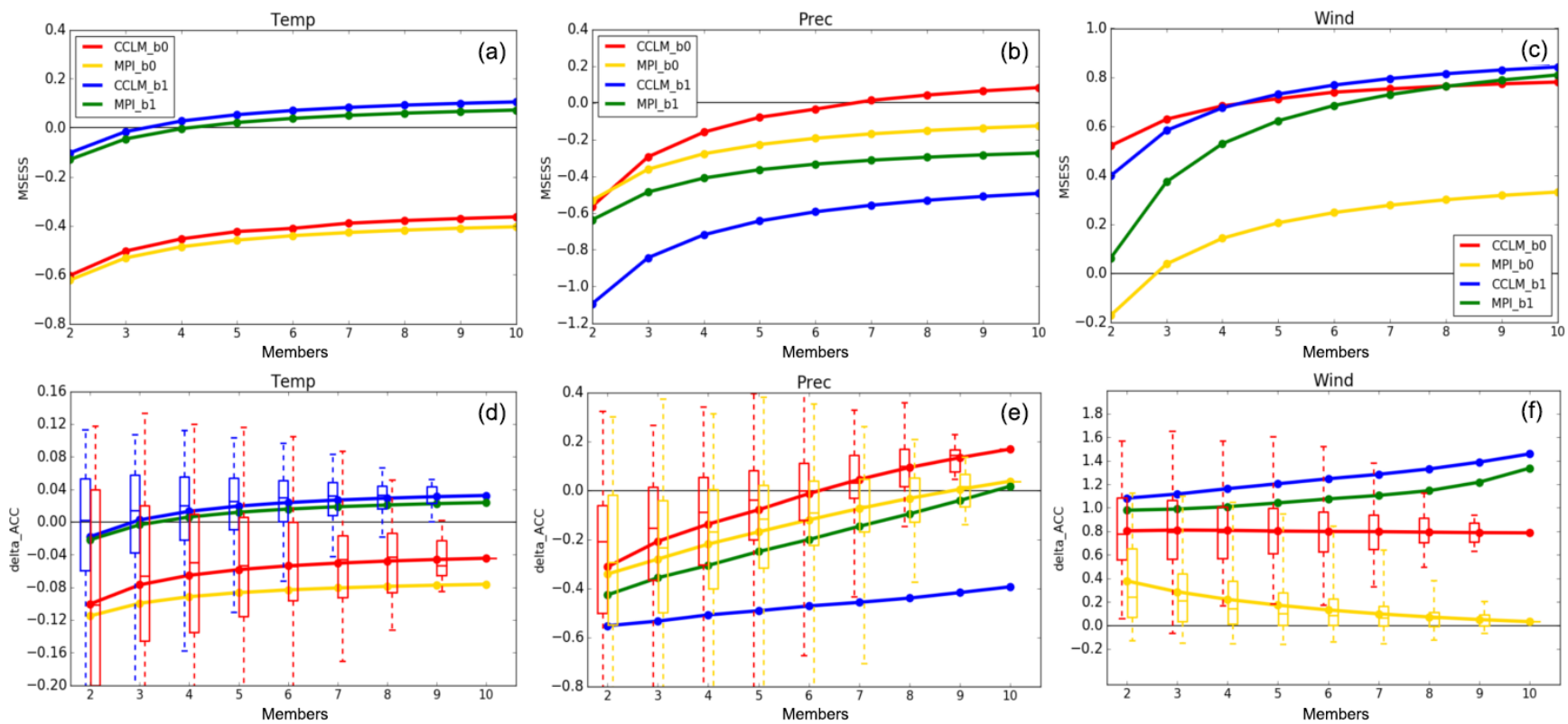

Figure 5. Skill scores for the multi-annual mean anomalies of lead years 1-5 of the CCLM_b0 (red), MPI_b0 (yellow), CCLM_b1 (blue), and MPI_b1 (green) ensembles depending on the ensemble size ( $x$ axis, ranging from 2 to 10 members) over IP (cf. Fig. 1). MSESS for (a) temperature, (b) precipitation, and (c) wind speed; delta_ACC for (d) temperature, (e) precipitation, and (f) wind speed. In (d)-(f) box and whisker plots for the skill scores of all $n$-member combinations are shown to indicate the uncertainty due to the ensemble size. For MSESS and delta_ACC we have used the uninitialized historical ensemble as reference dataset. Note the different scaling of the $y$ axis. For details, please refer to the main text.

variables over all eight PRUDENCE regions (not shown), regardless of whether the skill scores are negative or positive. In some cases, the ensemble size increase even leads to a shift from negative MSESS values to positive values in one or more of the ensembles (e.g. Fig. 5a and c). In contrast, no systematic conclusion can be stated for the delta_ACC, as the ensemble size dependency of the predictive skill depends on the variable and the considered MiKlip ensemble (Fig. 5d-f). Nevertheless, there are also examples for delta_ACC where the ensemble size dependency is similar to that of MSESS, e.g. for temperature (Fig. 5d). These results suggest that a regional decadal prediction system generally benefits from larger ensemble sizes, either in terms of more skilful decadal forecasts or at least of a reduction of the bias or the uncertainty, depending on the variable and the hindcast generation. Note that for most variables and skill scores the hindcast generation is more important for the skill than the resolution. In addition, most diagrams indicate an added value of downscaling. For temperature and wind speed, both generations of CCLM surpass their MPI counterparts for both skill scores, indicating a systematic added value of downscaling. This is particularly visible for wind in the b0 ensemble, where the prediction skill of CCLM is distinctly better than for MPIESM-LR (Fig. 5c and f). This is mainly due to higher skill scores over orographic structured terrains of IP in CLM_b0 compared to MPI_b0 (cf. Fig. 4).
For ensembles with less than 10 members, the skill scores of all possible $n$-member ensemble combinations are averaged. For selected ensembles, box and whisker plots of these $n$-member combinations are shown for delta_ACC in Fig. 5d-f. Given that we are doing permutations without replacement, the spread between the individual $n$-member ensembles declines with an increasing number of members $n$, and this decline should therefore not be over-interpreted. Nevertheless, the spread is quite large not only for small ensemble sizes but also for ensembles with $n>5$. For instance, delta_ACC for wind in CCLM_b0 (MPI_b0) varies between 0 and $+1.6(-0.1$ and +1.1$)$ for the 2 -member ensembles (Fig. 5f). Even for the 7-member ensemble, results can differ quite strongly depending on the selection of the ensemble members. Similar results are found for temperature and precipitation. These findings clearly demonstrate the necessity of using large ensembles to reduce uncertainties. Furthermore, only for high numbers of ensemble members (eight or more), the delta_ACC curve for CCLM_b0 is above the range of uncertainty in MPI_b0 in the case of precipitation (Fig. 5e) and wind (Fig. 5f). This indicates that the prediction skill may only be significantly improved when the whole ensemble is dynamically downscaled. The same applies for the improvement from baseline 0 to baseline 1 in the case of temperature (Fig. 5d).

In summary, our findings confirm what is already verified in recent studies for global decadal predictions: the predic- 
tive skill of a regional decadal prediction system is generally improved when the size of the hindcast ensembles increases. This is valid for all variables, regions, and hindcast ensembles considered in this study. The skill scores converge towards a certain value in most cases for MSESS in all hindcasts (see Fig. 5a-c). The increments in added value by increasing the number of ensemble members decrease for more than 5 members. Nevertheless, it is recommended to use 10 members or more for the skill assessment of decadal predictions on the regional scale, as is also endorsed in the Decadal Climate Prediction Project (DCPP) contribution to CMIP6 (Boer et al., 2016).

\subsection{How does the number of initializations affect the skill estimates?}

A lesson learned from the CMIP5 decadal experiments is that more starting years and thus a larger number of initializations is beneficial to establish robust skill estimates (Boer et al., 2016). This has been reflected in the progress from the first global MiKlip hindcast generation baseline0 to the second generation baseline 1 . Whereas baseline 0 provides 10 ensemble members every fifth year (compliant with the CMIP5 experimental protocol), baseline1 provides this ensemble size for each starting year of the hindcast period. To assess the impact of using only five initializations (as used elsewhere in the paper) on the robustness of our main conclusions we performed a sensitivity analysis with the global baseline 1 ensemble, for which all starting years are available. For this, we compared the sample with ten-yearly starting dates with the full yearly initialized MPI-ESM-LR baseline1 ensemble over the same period from 1960 to 2000.

Figure 6 presents a comparison between the ACC scores for the sample with five initializations (Fig. 6a, c, e) and the sample with all 41 initializations (Fig. 6b, d, f). For all three variables the score maps show in general comparable spatial distributions. The skill maps for the sample with all initializations usually depict a smoother spatial distribution with less extreme skill values and larger areas with significant skill scores. The regional averages over most of the PRUDENCE regions are comparable. However, in some regions larger differences can occur: for temperature over Ireland and Scotland, for precipitation over parts of France and eastern Europe, and for wind from northeastern Spain towards the Alps. Similar results are found for MSESS (not shown) for which not only the number of initializations of MPI_b1 is increased but also the number of uninitialized historical runs.

It is obvious that more initializations increase the robustness of the skill assessment, especially with respect to quantitative estimates and significance of the results. Therefore, this work supports the recommendations made for CMIP6 by Boer et al. (2016) to generate hindcast ensembles with yearly starting dates. Nevertheless, using only five initializations already represents the general features and to some extent the significance of the regional distribution. Therefore, the anal- ysis of the sample with all initializations confirms the qualitative findings from Sect. 4.1. The results regarding the added value and the ensemble size dependence are less affected by the number of initializations. Given the above findings, we conclude that the results obtained here for a limited number of initializations qualitatively comparable to those which would be obtained for samples with distinctly more initializations.

\section{Summary and discussion}

In this study, the decadal prediction skill of the regional MiKlip decadal prediction system is analysed for temperature, precipitation, and wind speed over Europe and compared to the forecast skill of the global ensemble. The goal is to assess the prospect of such a system for the application in forecasts on decadal timescales. Focus is given to years 1-5 after initialization. Two skill scores are used to quantify the accuracy of the two different MiKlip hindcast generations. The main findings of our study can be summarized as follows:

- There is a potential for regional decadal predictability over Europe for temperature, precipitation, and wind speed in the MiKlip system, but the predictive skill depends on the variable, the region, and the hindcast generation.

- The MiKlip prediction system may distinctly benefit from regional downscaling. An added value in terms of accuracy and to some extend significance of skill is particularly revealed for temperature over the British Isles (BI), Scandinavia (SC), the Iberian Peninsula (IP); and for precipitation over the British Isles (BI), Scandinavia (SC), Mid-Europe (ME), and France (FR) for the b1 generation. Most of these regions are characterized by complex coastlines and orography, which indicates that the better representation of topographic structures in the regionalized hindcasts may improve the predictive skill.

- The improvement of the initialization procedure from baseline 0 to baseline1 as described in Pohlmann et al. (2013b) increases the overall predictive skill in the downscaled MiKlip hindcasts over Europe, at least for precipitation and temperature. However, improvement of the skill varies between variable and region. The skill for temperature increases around the Mediterranean Sea and parts of Scandinavia from b0 to b1. For precipitation the skill of b1 compared to b0 is higher in all regions except the Iberian Peninsula and eastern Europe. Only for wind speed is there mostly no benefit from the improved initialization.

- A systematic enhancement of MSESS skill scores with increasing ensemble size, as revealed in numerous studies for global predictions, is also found for the regional 

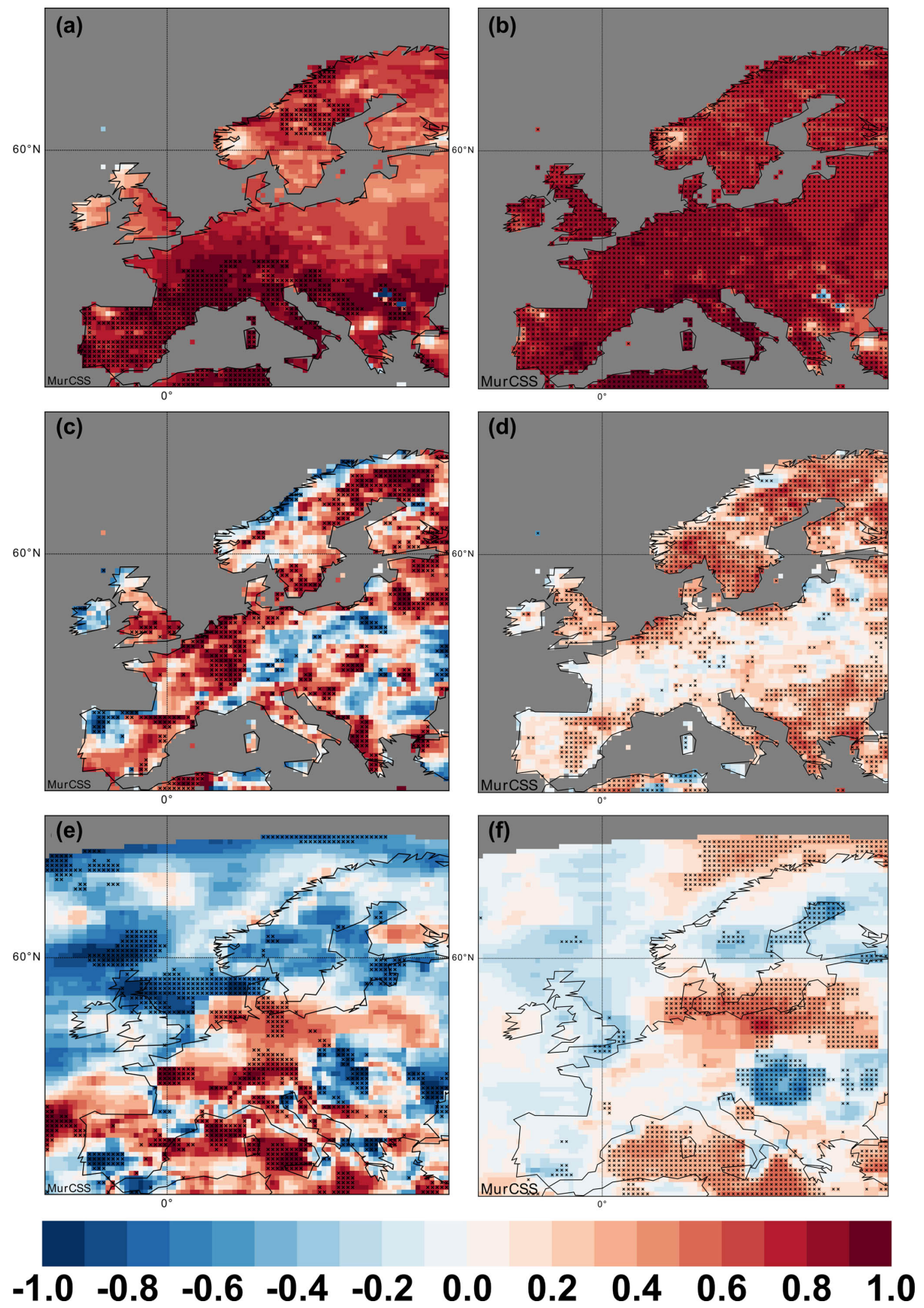

Figure 6. Spatial distribution of the ACC for the multi-annual mean anomalies of lead years 1-5 in MPI_b1 for (a, b) temperature, (c, d) precipitation, and (e, f) wind speed. For (a, c, e) five start years (dec1960, dec1970, dec1980, dec1990, dec2000) have been used, while for $(\mathbf{b}, \mathbf{d}, \mathbf{f})$ all start years from dec1960 to dec2000 are taken into account. The black dots indicate significant skill at the $95 \%$ level (bootstrapping). For more details see the main text.

MiKlip decadal predictions system, and 10 members is found to be suitable for regional decadal forecasts. This is valid for all variables and European regions.

- Based on the MPI_b1 data, it was shown that results derived from only five initializations used in this study qualitatively agree with results based on the full set of annual initializations. Nevertheless, such an increase would improve the robustness and significance of the skill maps.

Müller et al. (2012) and Pohlmann et al. (2013b) found systematic prediction skills for surface temperature over large parts of the North Atlantic and Europe in both global generations (baseline0, baseline1). From the results of our study, it is apparent that the Mediterranean area and the Iberian Penin- 
sula seem to be key European regions for decadal prediction skill with the regional prediction system. This is in line with findings from Guemas et al. (2015) and may be related to skilful predictions of the Atlantic Multi-decadal Oscillation (AMO; Garcia-Serrano et al., 2012; Guemas et al., 2015). Due to the rather non-linear relationship of these large-scale North Atlantic features to regional atmospheric conditions over Europe, the mechanisms steering the decadal variability and predictability of climate variables in European regions are thus more complex. The decadal variability in regional precipitation, temperature, and wind speed over most parts of Europe is largely affected by the North Atlantic Oscillation, but its skilful decadal predictability over the continent is still under debate. With respect to this, a better understanding of the mechanisms relevant for the regional climate over Europe on the decadal timescale is required, as was, for example, obtained for the tropical Atlantic (Dunstone et al., 2011). This is an objective of the ongoing second phase of the MiKlip project.

The skill scores may strongly vary between neighbouring grid points. Comparable results were found by Guemas et al. (2015), who detected a rather diffuse pattern for the accuracy of decadal predictions over Europe for seasonal temperature and precipitation. This might at least partly be due to spatial and temporal inhomogeneity of the gridded observational references. A more realistic assessment of the prediction skill can be made by considering spatial means (Goddard et al., 2013), which was mostly considered in this study. In line with Kadow et al. (2015), we could show that an enlargement of the ensemble size up to 10 members results in an improvement of the prediction skill over Europe. However, prediction skill could further benefit from even larger ensemble sizes, especially in areas with low signal-to-noise ratio (cf. Sienz et al., 2016).

Bias and drift adjustment (e.g. Boer et al., 2016) provides prospect in skill improvement not only for GCMs but also for RCMs. This is particularly the case for ensemble simulations run with full-field initialization (like the third MiKlip generation prototype, not analysed here; cf. Marotzke et al., 2016). While bias and drift adjustment methods have improved the forecast skill of near-term climate prediction (e.g. Kruschke et al., 2016), the general expectation is that drift correction is less important for prediction systems employing anomaly initializations like the baseline 0 and baseline 1 ensembles analysed here (Marotzke et al., 2016). Nevertheless, bias correction and calibration are an important topic in the second phase of MiKlip.

Due to the high computational costs of dynamical downscaling, only five initializations (one per decade) are available for the regional MiKlip ensemble (see Sect. 2). This is a shortcoming regarding the statistical significance of the results and some of the statements presented in this study. However, we could show that the qualitative findings are only partly influenced by the limited number of available hindcasts and that the main conclusions can be regarded as ro- bust. The statistical significance will be easier to quantify when the regional simulations for the newest MiKlip ensemble generation are available with annual starting dates over more than 50 years. On the other hand, regional decadal forecasts may have advantages beyond the examples discussed in this paper. For example, RCMs enable the integration of improved components of the hydrological cycle or climatesystem components with memory on multi-year timescales like soil moisture (Khodayar et al., 2014; Sein et al., 2015). Kothe et al. (2016) has shown that extracting the initial state of the deep soil in the RCMs from regional data assimilation schemes may improve decadal predictions. Further, Akhtar et al. (2017) demonstrated that the regional feedback between large water bodies and the atmosphere play a major in the regional climate system. This feedback can only be captured in regionalized climate predictions by a dynamic RCM-ocean coupling. Most of the approaches mentioned above are ongoing within the second phase of MiKlip and are expected to enhance the decadal prediction skill over Europe. We thus conclude that a decadal prediction system would clearly benefit from a regional forecast ensemble.

The regional decadal prediction system generated by the MiKlip consortium comprises altogether 1000 years (two hindcast generations, each of them comprising 10 hindcast members for five starting years) of simulations with $0.22^{\circ}$ for the entire EURO-CORDEX region, which is, to our best knowledge, unprecedented. Hence, this ensemble enabled us to gain important insights into different aspects and the prospects of regional downscaling for decadal predictions, and serve as a good basis for future studies. In the ongoing second phase of MiKlip it is planned to downscale a complete ensemble hindcast generation with 10 members for more than 50 starting years, giving altogether more than 5000 years. These regional hindcast ensembles provide a valuable dataset beyond decadal predictions, as they comprise multiple realizations of the present-day climate in comparably high resolution, which can for instance be used to determine more robust return periods for extreme events.

Data availability. The MiKlip data will be made available via the CERA database (http://cera-www.dkrz.de/, last access: June 2018) of the German Climate Computing Center (DKRZ).

Author contributions. MR, HF, SM, and MU developed the concept of the paper; MR, HF, and JGP wrote the first manuscript draft. MR, HF, SM, MU, NL, and JM contributed with data analysis and analysis tools. HF, SM, MR, BA, and BF contributed with RCM simulations. MK and WM contributed with the global MPI-ESMLR simulations and prepared boundary conditions for RCM simulations. CK leads the MiKlip-C consortium, with project leaders BA, BF, JGP, and GS. All authors contributed with ideas, interpretation of the results, and manuscript revisions. 
Competing interests. The authors declare that they have no conflict of interest.

Acknowledgements. MiKlip is funded by the German Federal Ministry for Education and Research (BMBF, contracts: 01LP1518 A-D and 01LP1519) All simulations were carried out at the German Climate Computing Centre (DKRZ), which also provided all major data services. We acknowledge the E-OBS dataset from the EU-FP6 project ENSEMBLES (http://ensembles-eu. metoffice.com, last access: September 2016) and the data providers in the ECA \& D project (http://www.ecad.eu, last access: September 2016). We thank the European Centre for Medium-Range Weather Forecasts (ECMWF) for their ERA-40 and ERA-Interim reanalysis data (http://apps.ecmwf.int/datasets/, last access: December 2018). Joaquim G. Pinto thanks the AXA Research Fund for support. We thank past and present members of the MiKlip-C (Regionalization) group for discussions and comments, and Christopher Kadow and Sebastian Illing for providing the MiKlip Central Evaluation System (MiKlip CES). We thank the reviewers for their comments, which helped to improve the manuscript.

Review statement. This paper was edited by Andrey Gritsun and reviewed by three anonymous referees.

\section{References}

Akhtar, N., Brauch, J., and Ahrens, B.: Climate Modeling over the Mediterranean Sea: Impact of Resolution and Ocean Coupling, Clim. Dynam., 51, 933-948, https://doi.org/10.1007/s00382017-3570-8, 2017.

Balmaseda, M. A., Mogensen, K., and Weaver, A. T.: Evaluation of the ECMWF ocean reanalysis system ORAS4, Q. J. Roy. Meteorol. Soc., 139, 1132-1161, https://doi.org/10.1002/qj.2063, 2013.

Benestad, R. E. and Mezghani, A.: On downscaling probabilities for heavy 24-hour precipitation events at seasonal-to-decadal scales, Tellus A, 67, 25954, https://doi.org/10.3402/tellusa.v67.25954, 2015.

Berg, P., Wagner, S., Kunstmann, S., and Schaedler, G.: High resolution regional climate model simulations for Germany: part I validation, Clim. Dynam., 40, 401-414, 2013.

Boer, G. J., Smith, D. M., Cassou, C., Doblas-Reyes, F., Danabasoglu, G., Kirtman, B., Kushnir, Y., Kimoto, M., Meehl, G. A., Msadek, R., Mueller, W. A., Taylor, K. E., Zwiers, F., Rixen, M., Ruprich-Robert, Y., and Eade, R.: The Decadal Climate Prediction Project (DCPP) contribution to CMIP6, Geosci. Model Dev., 9, 3751-3777, https://doi.org/10.5194/gmd-9-3751-2016, 2016.

Chikamoto Y., Kimoto, M., Ishii, M., Mochizuki, T., Sakamoto, T. T., Tatebe, H., Komuro, Y., Watanabe, M., Nozawa, T., Shiogama, H., Mori, M., Yasunaka, S., and Imada, Y.: An overview of decadal climate predictability in a multi-model ensemble by climate model MIROC, Clim. Dynam., 40, 12011222, https://doi.org/10.1007/s00382-012-1351-y, 2012.

Christensen, J. H. and Christensen, O. B.: A summary of the PRUDENCE model projections of changes in European cli- mate by the end of this century, Climatic Change, 81, 7-30, https://doi.org/10.1007/s10584-006-9210-7, 2007.

Corti S., Palmer, T., Balmaseda, M., Weisheimer, A., Drijfhout, S., Dunstone, N., Hazeleger, W., Kröger, J., Pohlmann, H., Smith, D., von Storch, J.-S., and Wouters, B.: Impact of Initial Conditions versus External Forcing in Decadal Climate Predictions: A Sensitivity Experiment, J. Climate, 28, 4454-4470, https://doi.org/10.1175/JCLI-D-14-00671.1, 2015.

Dee, D. P., Uppala, S. M., Simmons, A. J., Berrisford, P., Poli, P., Kobayashi, S., Andrae, U., Balmaseda, M. A., Balsamo, G., Bauer, P., Bechtold, P., Beljaars, A. C. M., van de Berg, L., Bidlot, J.,Bormann, N., Delsol, C., Dragani, R., Fuentes, M., Geer, A. J., Haimberger, L., Healy, S. B., Hersbach, H., Holm, E. V., Isaksen, L., Kallberg, P., Köhler, M., Matricardi, M., McNally, A. P., Monge-Sanz, B. M., Morcrette, J.-J., Park, B.-K., Peubey, C., de Rosnay, P., Tavolato, C., Thepaut, J.-N., and Vitart, F.: The ERA-Interim reanalysis: configuration and performance of the data assimilation system, Q. J. Roy. Meteorol. Soc., 137, 553597, https://doi.org/10.1002/qj.828, 2011.

Doblas-Reyes, F. J., Andreu-Burillo, I., Chikamoto, Y., GarcíaSerrano, J., Guemas, V., Kimoto, M., Mochizuki, T., Rodrigues, L. R. L., and van Oldenborgh, G. J.: Initialized near-term regional climate change prediction, Nat. Commun., 4, 1715, https://doi.org/10.1038/ncomms2704, 2013.

Dunstone, N. J., Smith, D. M., and Eade, R.: Multi-year predictabilityof the tropical Atlantic atmosphere driven by the high latitude North Atlantic Ocean, Geophys. Res. Lett., 38, L14701, https://doi.org/10.1029/2011GL047949, 2011.

Eade, R., Hamilton, E., Smith, D. M., Graham, R. J., and Scaife, A. A.: Forecasting the number of extreme daily events out to a decade ahead, J. Geophys. Res., 117, D21110, https://doi.org/10.1029/2012JD018015, 2012.

Feldmann, H., Schaedler, G., Panitz, H.-J., and Kottmeier, C.: Near future changes of extreme precipitation over complex terrain in Central Europe derived from high resolution RCM ensemble simulations, Int. J. Climatol., 33, 1964-1977, 2013.

Ferro, C. A. T., Richardson, D. S., and Weigel, A. P.: On the effect of ensemble size on the discrete and continuous ranked probability scores, Meteorol. Appl., 15, 19-24, https://doi.org/10.1002/met.45, 2008.

Garcia-Serrano, J., Doblas-Reyes, F. J., and Coelho, C. A. S.: Understanding Atlantic multi-decadal variability prediction skill, Geophys. Res. Lett., 39, L18708, https://doi.org/10.1029/2012GL053283, 2012.

Giorgetta, M. A., Jungclaus, J. J., Reick, C. H., Legutke, S., Bader, J., Böttinger, M. and Brovkin, V., Crueger, T., Esch, M., Fieg, K., Glushak, K., Gayler, V., Haak., H., Hollweg, H.-D., Ilyina, T., Kinne, S., Kornblueh, L., Matei, D., Mauritsen, T., Mikolajewicz., U., Mueller, W. A., Notz, D., Pithan, F., Raddatz, T., Rast, S., Redler, R., Roeckner, E., Schmidt, H., Schnur, R., Segschneider, J., Six, K. D., Stockhause, M., Timmreck, C., Wegner, J., Widmann, H., Wieners, K.-H., Claussen, M., Marotzke, J., and Stevens, B.: Climate and carbon cycle changes from 1850 to 2100 in MPI-ESM simulations for the Coupled Model Intercomparison Project phase 5, J. Adv. Model. Earth Syst., 5, 572597, https://doi.org/10.1002/jame.20038, 2013.

Giorgi, F., Jones, C., and Asrar, G. R.: Addressing climate information needs at the regional level: the CORDEX framework, Bull. World Meteorol. Org., 58, 175-183, 2009. 
Goddard, L., Kumar, A., Solomon, A., Smith, D., Boer, G., Gonzalez, P., Kharin, V., Merryfield, W., Deser, C., Mason, S. J., Kirtman, B. P., Msadek, R., Sutton, R., Hawkins, E., Fricker, T., Hegerl, G., Ferro, C. A. T., Stephenson, D. B., Meehl, G. A., Stockdale, T., Burgman, R., Greene, A. M., Kushnir, Y., Newman, M., Carton, J., Fukumori, I., and Delworth, T.: A verification framework for interannual-todecadal predictions experiments, Clim. Dynam., 40, 245-272, https://doi.org/10.1007/s00382-012-1481-2, 2013.

Guemas V., García-Serrano, J., Mariotti, A., Doblas-Reyes, F., and Caron, L.-P.: Prospects for decadal climate prediction in the Mediterranean region, Q. J. Roy. Meteorol. Soc., 141, 580-597, https://doi.org/10.1002/qj.2379, 2015.

Hackenbruch, J., Schaedler, G., and Schipper, J. W.: Added value of high-resolution regional climate simulations for regional impact studies, Meteorol. Z., 25, 291-304, https://doi.org/10.1127/metz/2016/0701, 2016.

Haas, R., Reyers, M., and Pinto, J. G.: Decadal predictability of regional-scale peak winds over Europe based on MPI-ESM-LR, Meteorol. Z., 25, 739-752, https://doi.org/10.1127/metz/2015/0583, 2016.

Haylock, M. R., Hofstra, N., Klein Tank, A. M. G., Klok, E. J., Jones, P. D., and New, M.: A European daily highresolution gridded data set of surface temperature and precipitation for 1950-2006, J. Geophys. Res., 113, D20119, https://doi.org/10.1029/2008JD010201, 2008.

Ho, C. K., Hawkins, E., Shaffrey, L., Bröcker, J., Hermanson, L., Murphy, J. M., Smith, D. M., and Eade, R.: Examining reliability of seasonal to decadal sea surface temperature forecasts: The role of ensemble dispersion, Geophys. Res. Lett., 40, 5770-5775, https://doi.org/10.1002/2013GL057630, 2013.

Jungclaus, J. H., Fischer, N., Haak, H., Lohmann, K., Marotzke, J., Matei, D., Mikolajewicz, U., Notz, D., and von Storch, J.-S.: Characteristics of the ocean simulations in MPIOM, the ocean component of the MPI-Earth system model, J. Adv. Model. Earth Syst., 5, 422-446, https://doi.org/10.1002/jame.20023, 2013.

Kadow, C., Illing, S., Kunst, O., Rust, H. W., Pohlmann, H., Müller, W. A., and Cubasch, U.: Evaluation of forecasts by accuracy and spread in the MiKlip decadal climate prediction system, Meteorol. Z., 25, 631-643, https://doi.org/10.1127/metz/2015/0639, 2015.

Kalnay, E., Kanamitsu, M., Kistler, R., Collins, W., Deaven, D., Gandin, L., Iredell, M., Saha, S., White, G., Woollen, J., Zhu, Y., Leetmaa, A., Reynolds, R., Chelliah, M., Ebisuzaki, W., Higgins, W., Janowiak, J., Mo, K. C., Ropelewski, C. Wang, J., Jenne, R., and Joseph, D.: The NCEP/NCAR 40-Year Reanalysis Project, B. Am. Meteorol. Soc., 77, 437-471, https://doi.org/10.1175/15200477(1996)077<0437:TNYRP>2.0.CO;2, 1996.

Khodayar, S., Selinger, A., Feldmann, H., and Kottmeier, C.: Sensitivity of soil moisture initialization for decadal predictions under different regional climatic conditions in Europe, Int. J. Climatol., 35, 1899-1915, https://doi.org/10.1002/joc.4096, 2014.

Kothe, S., Tödter, J., and Ahrens, B.: Strategies for soil initialisation in regional decadal climate predictions, Meteorol. Z., 25, 775794, https://doi.org/10.1127/metz/2016/0729, 2016.

Kröger, J., Müller, W. A., and von Storch, J.-S.: Impact of different ocean reanalyses on decadal climate prediction, Clim. Dynam., 39, 795-810, https://doi.org/10.1007/s00382-012-1310-7, 2012.
Kruschke, T., Rust, H. W., Kadow, C., Leckebusch, G. C., and Ulbrich, U.: Evaluating decadal predictions of northern hemispheric cyclone frequencies, Tellus A, 66, 22830, https://doi.org/10.3402/tellusa.v66.22830, 2014.

Kruschke, T., Rust, H. W., Kadow, C., Müller, W. A., Pohlmann, H., Leckebusch, G. C., and Ulbrich, U.: Probabilistic evaluation of decadal prediction skill regarding Northern Hemisphere winter storms, Meteorol. Z., 25, 721-738, https://doi.org/10.1127/metz/2015/0641, 2016.

Li, H., Ilyina, T., Müller, W. A., and Sienz, F.: Decadal predictions of the North Atlantic $\mathrm{CO}_{2}$ uptake, Nat. Commun., 7, 11076, https://doi.org/10.1038/ncomms11076, 2016.

Marotzke J., Müller, W. A., Vamborg, F. S. E., Becker, P., Cubasch, U., Feldmann, H., Kaspar, F., Kottmeier, C., Marini, C., Polkova, I., Prömmel, K., Rust, H. W., Rust, H. W., Stammer, D., Ulbrich, U., Kadow, C., Köhl, A., Kröger, J., Kruschke, T., Pinto, J. G., Pohlmann, H., Reyers, M., Schröder, M., Sienz, F., Timmreck, C., and Ziese, M.: MiKlip - a National Research Project on Decadal Climate Prediction, B. Am. Meteorol. Soc., 97, 23792393, https://doi.org/10.1175/BAMS-D-15-00184.1, 2016.

Matei, D., Pohlmann, H., Jungclaus, J. H., Müller, W. A., Haak, H., and Marotzke, J.: Two tales of initializing decadal climate prediction experiments with the ECHAM5/MPI-OM model, J. Climate, 8502-8523, https://doi.org/10.1175/JCLI-D-11-00633.1, 2012.

Meehl, G. A., Goddard, L., Murphy, J., Stouffer, R. J., Boer, G., Danabasoglu, G., Dixon, K., Giorgetta, M. A., Greene, A. M., Hawkins, E., Hegerl, G., Karoly, D., Keenlyside, N. S., Kimoto, M., Kirtman, B., Navarra, A., Pulwarty, R., Smith, D., Stammer, D., and Stockdale, T.: Decadal Prediction, B. Am. Meteorol. Soc., 90, 1467-1485, https://doi.org/10.1175/2009BAMS2778.1, 2009.

Meehl, G. A., Goddard, L., Boer, G., Burgman, R., Branstator, G., Cassou, C., Corti S., Danabasoglu, G., Doblas-Reyes, F., Hawkins, E., Karspeck, A., Kimoto, M., Kumar, A., Matei, D., Mignot, J., Msadek, R., Navarra, A., Pohlmann, H., Rienecker, M., Rosati, T., Schneider, E., Smith, D., Sutton, R., Teng, H., van Oldenborgh, G. J., Vecchi, G., and Yeager, S.: Decadal Climate Prediction: An Update from the Trenches, B. Am. Meteorol. Soc., 95, 243-267, https://doi.org/10.1175/BAMS-D-12$00241.1,2014$.

Mieruch, S., Feldmann, H., Schädler, G., Lenz, C.-J., Kothe, S., and Kottmeier, C.: The regional MiKlip decadal forecast ensemble for Europe: the added value of downscaling, Geosci. Model Dev., 7, 2983-2999, https://doi.org/10.5194/gmd-7-2983-2014, 2014.

Moemken, J., Reyers, M., Buldmann, B., and Pinto, J. G.: Decadal predictability of regional scale wind speed and wind energy potentials over Central Europe, Tellus A, 68, 29199, https://doi.org/10.3402/tellusa.v68.29199, 2016.

Müller, W. A., Baehr, J., Haak, H., Jungclaus, J. H., Kröger, J., Matei, D., Notz, D., Pohlmann, H., von Storch, J.-S., and Marotzke, J.: Forecast skill of multi-year seasonal means in the decadal prediction system of the Max Planck Institute for Meteorology, Geophys. Res. Lett., 39, L22707, https://doi.org/10.1029/2012GL053326, 2012.

Murphy, A. H.: Skill Scores Based on the Mean Square Error and Their Relationships to the Correlation Coefficient, Mon. Weather Rev., 116, 2417-2424, https://doi.org/10.1175/15200493(1988)116<2417:SSBOTM>2.0.CO;2, 1988. 
Pohlmann, H., Smith, D. M., Balmaseda, M. A., Keenlyside, N. S., Masina, S., Matei, D., Müller, W. A., and P. Rogel, P.: Predictability of the mid-latitude Atlantic meridional overturning circulation in a multi-model system, Clim. Dynam., 41, 775-785, https://doi.org/10.1007/s00382-013-1663-6, 2013a.

Pohlmann, H., Müller, W. A., Kulkarni, K., Kameswarrao, M., Matei, D., Vamborg, F. S. E., Kadow, C., Illing, S., and Marotzke, J.: Improved forecast skill in the tropics in the new MiKlip decadal climate predictions, Geophys. Res. Lett., 40, 5798-5802, https://doi.org/10.1002/2013GL058051, 2013b.

Richardson, D. S.: Measures of skill and value of ensemble predictions systems, their interrelationship and the effect of ensemble size, Q. J. Roy. Meteorol. Soc., 1277, 2473-2489, https://doi.org/10.1002/qj.49712757715, 2001.

Robson, J., Sutton, R., and Smith, D.: Predictable climate impacts of the decadal changes in the ocean in the 1990s, J. Climate, 26, 6329-6339, https://doi.org/10.1175/JCLI-D-12-00827.1, 2013.

Rockel, B., Will, A., and Hense, A.: The Regional Climate Model COSMO-CLM (CCLM), Meteorol. Z., 17, 347-348, https://doi.org/10.1127/0941-2948/2008/0309, 2008.

Scaife, A. A., Arribas, A., Blockley, E., Brookshaw, A., Clark, R. T., Dunstone, N., Eade, R., Fereday, D., Folland, C. K., Gordon, M., Hermanson, L., Knight, J. R., Lea, D. J., MacLachlan, C., Maidens, A., Martin, M., Peterson, A. K., Smith, D., Vellinga, M., Wallace, E., Waters, J., and Williams, A.: Skillful long-range prediction of European and North American Winters, Geophys. Res. Lett., 41, 2514-2519, https://doi.org/10.1002/2014GL059637, 2014.

Sein, D. V., Mikolajewicz, U., Gröger, M., Fast, I., Cabos, W., Pinto, J. G., Hagemann, S., Semmler, T., Izquierdo, A., and Jacob, D.: Regionally coupled atmosphere-oceansea ice-marine biogeochemistry model ROM: 1. Description and validation, J. Adv. Model. Earth Syst., 7, 268-304, https://doi.org/10.1002/2014MS000357, 2015.
Sienz, F., Müller, W. A., and Pohlmann, H.: Ensemble size impact on the decadal predictive skill assessment, Meteorol. Z., 25, 645655, 2016.

Smith, D. M., Scaife, A. A., and Kirtman, B. P.: What is the current state of scientific knowledge with regard to seasonal and decadal forecasting?, Environ. Res. Lett., 5, 015602, https://doi.org/10.1088/1748-9326/7/1/015602, 2012.

Stevens, B., Giorgetta, M. A., Esch, M., Mauritsen, T., Crueger, T., Rast, S., Salzmann, M., Schmidt, H., Bader, J., Block, K., Brokopf, R., Fast, I., Kinne, S., Kornblueh, L., Lohmann, U., Pincus, R., Reichler, T., and Roeckner, E.: Atmospheric component of the MPI-M Earth System Model: ECHAM6, J. Adv. Model. Earth Syst., 5, 146-172, https://doi.org/10.1002/jame.20015, 2013.

Taylor, K. E., Stouffer, R. J., and Meehl, G. A.: An Overview of CMIP5 and the Experiment Design, B. Am. Meteorol. Soc., 93, 485-498, https://doi.org/10.1175/BAMS-D-11-00094.1, 2012.

Uppala, S. M., KÅllberg, P. W., Simmons, A. J., Andrae, U., Bechtold, V. D. C., Fiorino, M., Gibson, J. K., Haseler, J., Hernandez, A., Kelly, G. A., Li, X., Onogi, K., Saarinen, S., Sokka, N., Allan, R. P., Andersson, E., Arpe, K., Balmaseda, M. A., Beljaars, A. C. M., Van De Berg, L., Bidlot, J., Bormann, N., Caires, S., Chevallier, F., Dethof, A., Dragosavac, M., Fisher, M., Fuentes, M., Hagemann, S., Hólm, E., Hoskins, B. J., Isaksen, L., Janssen, P. A. E. M., Jenne, R., Mcnally, A. P., Mahfouf, J.-F., Morcrette, J.-J., Rayner, N. A., Saunders, R. W., Simon, P., Sterl, A., Trenberth, K. E., Untch, A., Vasiljevic, D., Viterbo, P., and Woollen, J.: The ERA-40 re-analysis, Q. J. Roy. Meteorol. Soc., 131, 2961-3012, https://doi.org/10.1256/qj.04.176, 2005.

Wilks, D. S.: Statistical Methods in the Atmospheric Sciences, 3rd revised edition, Academic Press, Oxford, UK, 2011.

Yeager, S., Karspeck, A., Danabasoglu, G., Tribbia, J., and Teng, H.: A decadal prediction case study: Late twentieth-century North Atlantic Ocean heat content, J. Climate, 25, 5173-5189, https://doi.org/10.1175/JCLI-D-11-00595.1, 2012. 